\title{
Itinerários formativos na BNCC do Ensino Médio: identificações docentes e projetos de vida juvenis ${ }^{1}$
}

\section{Formative itineraries at BNCC of High School:}

teacher identifications and youth life projects

\author{
Itinerarios de formación en la BNCC de la Escuela Secundaria: \\ Identificaciones docentes y proyectos de vida juveniles
}

ALICE CASIMIRO LOPES*

Universidade do Estado do Rio de Janeiro, Rio de Janeiro- RJ. Brasil

\begin{abstract}
RESUMO: São discutidas as relações entre disciplinas escolares e propostas de integração nas políticas de currículo, com foco na proposta de itinerários formativos e de organização por competências da Base Nacional Comum Curricular para o ensino médio, destacando alguns efeitos que produzem nas identificações docentes, bem como as tentativas de controle dos projetos de vida dos estudantes. O artigo conclui que a proposta de integração curricular apresentada pela BNCC do ensino médio não viabiliza a flexibilidade curricular a qual alude, pelo contrário, tende a ser restritiva de possibilidades de integração curricular por permanecer tentando controlar o projeto de futuro dos jovens estudantes por meio de metas fixadas a priori.
\end{abstract}

Palavras-chave: BNCC. Itinerário formativo. Organização curricular. Política de currículo.

\begin{abstract}
The relationships between school disciplines and integration propositions in curriculum policies are discussed, with a focus on the proposal of formative itineraries and organization by competences of the National Curricular Common Core for high school, highlighting some effects produced in the teachers' identifications as well as attempts to control students' life projects. The article concludes that
\end{abstract}

* Alice Casimiro Lopes é professora do Programa de Pós-gradução em Educação (ProPEd) da Uerj, PQ 1 B do CNPq, Cientista do Nosso Estado Faperj, Procientista Uerj/Faperj. ORCID orcid.org/0000-0001-99439117. E-mail: <alicecasimirolopes@gmail.com>. 
the proposition of curricular integration presented by BNCC of high school does not allow the curricular flexibility that alludes. On the contrary, it tends to be restrictive of possibilities of curricular integration for persisting on trying to control the future project of the young students through goals primarily set.

Keywords: BNCC. Formative itinerary. Curricular organization. Curriculum policy.

RESUMEN: Se discuten las relaciones entre las disciplinas escolares y las propuestas para la integración en las políticas de currículo, centrándose en la propuesta de itinerarios formativos y de organización por competencias de la Base Nacional Común Curricular (BNCC) para la escuela secundaria, destacando algunos efectos que producen en las identificaciones docentes, así como los intentos de control de los proyectos de la vida de los estudiantes. El artículo concluye que la propuesta de integración curricular presentada por la BNCC para la enseñanza secundaria no permite la flexibilidad curricular que alega, por el contrario, tiende a restringir las posibilidades de integración curricular al tratar de controlar el proyecto de futuro de los jóvenes estudiantes a través de metas establecidas a priori.

Palabras clave: BNCC. Itinerario formativo. Organización curricular. Política curricular.

\section{Apresentando o foco e o contexto}

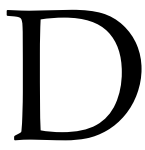

iante do tema proposto para este dossiê, considero importante inicialmente fazer o registro de uma posição política, mesmo que muitos dos leitores de Retratos da Escola possam conhecer tal posição. Ao reiterar tal registro, tenho a expectativa de que minha argumentação neste artigo seja lida no contexto desta posição.

Sou contrária à instituição de uma base curricular no País, seja ela a Base Nacional Comum Curricular (BNCC), assinada pelo governo Dilma, ou a BNCC assinada pelo governo Temer e que será "implementada" - com todas as reservas que tenho ao termo implementação - no governo Bolsonaro. Como já afirmei anteriormente (Cunha \& Lopes, 2017; Lopes, 2015 \& 2018a), uma base curricular comum, tal como organizada no País, pressupõe apostar em um registro estabelecido como tendo um selo oficial de verdade, um conjunto de conteúdos que adquire o poder de conhecimento essencial a ser ensinado e aprendido, metas uniformes e projetos identitários fixos, trajetórias de 
vida preconcebidas, esforços para tentar conter a tradução e impor uma leitura curricular como a única correta e obrigatória. Pressupõe apostar no consenso curricular como se ele fosse possível fora da disputa política contingente. Pressupõe ainda situar o debate e a deliberação política em uma etapa anterior ao texto promulgado, como se uma vez estabelecida a base, a política, com seus conflitos e antagonismos, cessasse.

Por isso, reafirmo não ser necessário nem possível que o currículo seja o mesmo em todas as escolas. O currículo precisa fazer sentido e ser construído contextualmente, atender demandas e necessidades que não são homogêneas. É próprio de qualquer textualização, dentre elas a textualização curricular, ser submetida à interpretação, sendo realizada de forma imprevisível. Nunca é uma interpretação completa (pura diferença), sem referência ao texto, nunca é o suposto caos do qualquer um entende o que bem quiser.

Seja porque há tradições curriculares que balizam a intepretação, seja porque há relações de poder que limitam os possíveis sentidos, a interpretação tem seus limites contextuais, sendo sempre associada às dinâmicas contingentes.

Tendo em vista essa posição política frente à BNCC, me proponho a focalizar a discussão sobre as relações entre disciplinas escolares e propostas de integração nas políticas de currículo, com foco na proposta de itinerários formativos e de organização por competências da BNCC para o ensino médio (Brasil, 2018a), destacando alguns efeitos que produzem (ou podem vir a produzir) nas identificações docentes.

Ao longo da história do currículo, há diferentes formas de organização curricular (Lopes, 2008), de forma geral referenciadas a diferentes modos de significar as disciplinas escolares. Tais formas de organização podem ser agrupadas em: integração pelas competências e habilidades a serem formadas nos alunos; foco instrumental vinculado à organização curricular por competências; integração de conceitos das disciplinas mantendo a lógica dos saberes disciplinares de referência, caso em que se situa a proposta de interdisciplinaridade; integração via interesses dos alunos e/ou buscando referência nas questões sociais e políticas mais amplas, proposta usualmente associada ao currículo por projetos, centros de interesse e temas transversais.

Nessa perspectiva, disciplinaridade e integração não são polos que se opõem, de forma que se possa pensar em uma alternância entre currículo disciplinar e currículo integrado (Lopes, 2008). Ainda que ao longo da história do currículo ocidental exista uma estabilidade do currículo disciplinar (Macedo \& Lopes, 2002), uma hegemonia das formas de organização por disciplinas escolares, essa estabilidade não apaga diferentes formas de organização curricular integrada que permanecem sendo desenvolvidas nas instituições escolares, inclusive com a existência de disciplinas constituídas de forma integrada, tais como Ciências (que integra Química, Física, Biologia, princípios de Astronomia, de Geologia), Estudos Sociais (que integra História, Geografia, Sociologia), dentre tantas outras.

Se considerarmos os últimos vinte anos, é possível afirmar que as propostas curriculares e textos normativos assinados pelo MEC ou por Secretarias de Educação nos estados 
e municípios brasileiros têm expressado as lutas políticas por flexibilização curricular, usualmente associadas à inovação e à maior adequação à contemporaneidade do social: interdisciplinaridade e contextualização, competências, temas transversais, currículo por ciclos. Todavia, mesmo quando tais propostas apenas recuperam antigas tradições curriculares integradas de viés instrumental, como o currículo por competências, assumem uma ambivalência que leva tanto ao questionamento das disciplinas escolares - como tradicionais, retrógradas, desvinculadas dos interesses dos alunos e alunas - quanto à reafirmação das disciplinas. Na BNCC da Educação Básica, por exemplo, busca-se (...) a superação da fragmentação radicalmente disciplinar do conhecimento, ao mesmo tempo em que é proposta uma organização por áreas que (...) não excluem necessariamente as disciplinas, com suas especificidades e saberes próprios historicamente construídos, mas, sim, implicam o fortalecimento das relações entre elas (BRASIL, 2018a: 13; ênfases no original).

Não obstante, certa novidade se constata na inversão do que vem marcando as relações entre os níveis de ensino e a organização disciplinar no Brasil. O ensino fundamental, que em sua história esteve mais associado às atividades integradas que aos poucos foram sendo disciplinarizadas, tem uma proposta de organização que menciona componentes curriculares obrigatórios associados às usuais disciplinas escolares desse nível de ensino. No ensino médio, por sua vez, Língua Portuguesa e Matemática são as únicas disciplinas com habilidades específicas, que precisarão ser trabalhadas obrigatoriamente durante toda a extensão do Ensino Médio (Brasil, 2018b: 11). Além disso, a BNCC para o ensino médio, em direção oposta ao que é feito pela BNCC do ensino fundamental, não indica habilidades a serem desenvolvidas por anos ou por disciplinas nem estabelece sequências ou simultaneidades, de forma a tornar o currículo ainda mais flexível.

Desse modo, formas de organização integrada ganham maior visibilidade na BNCC do ensino médio. As disciplinas são questionadas de forma mais contundente, chegando a ser afirmado que o objetivo é quebrar a centralidade das disciplinas no processo de ensino-aprendizagem (Brasil, 2018b: p. 39). As disciplinas escolares parecem assim ser o principal alvo a ser combatido pela reforma, não só pela quantidade delas no currículo vigente, como pelo modo como supostamente estariam funcionando no ensino médio. As disciplinas são significadas como descontextualizadas, como capazes de apoiar uma visão fragmentada de mundo, consolidando uma formação superficial e extensa dos jovens, além de serem empecilho a uma diversificação dos sistemas de ensino, em função da carga horária que ocupam na grade escolar. As disciplinas do ensino médio são então subsumidas à organização por áreas (que remete às Diretrizes Curriculares de 1998, com algumas mudanças) e aos itinerários formativos.

Nesse embate, não parecem ser consideradas a concepção de disciplina escolar e as implicações de mudanças na organização curricular. Disciplinas escolares não são simples divisões epistemológicas de saberes derivados de disciplinas acadêmicas. Goodson (1983), em trabalho antigo ainda hoje emblemático, discute como as disciplinas escolares 
orientam a produção de diplomas, o cumprimento de exigências sociais, os critérios para formação de professores, a divisão do trabalho docente, mecanismos que são sustentados e ao mesmo tempo sustentam as comunidades disciplinares.

As disciplinas escolares, nesse sentido, não são "boas" ou "ruins", "certas" ou "erradas" em si. São instituições educativas com as quais é negociada a significação da política curricular. Propor uma mudança de organização curricular na qual as disciplinas escolares são mencionadas como se fossem apenas divisões de conhecimento que precisam ser reagrupadas desconsidera que, como instituições, tais disciplinas organizam comunidades que constituem identificações sociais. Portanto, alterar a organização curricular implica modificar identificações docentes.

Inserindo tal discussão em um registro pós-fundacional (Costa \& Lopes, 2016; 2018), tais comunidades disciplinares remetem à heterogeneidade social. As comunidades disciplinares não têm algo (um saber, uma identidade, um registro de verdade) em comum que garanta sua essência e sua coesão. Como construções discursivas, tais comunidades são sociais e históricas, mas também remetem à contingência. Isso faz com que, independentemente da organização curricular proposta, de ser afirmada ou não a obrigatoriedade das disciplinas escolares, as políticas curriculares, para se instituírem, produzem articulações com demandas das comunidades disciplinares. Em certas relações de poder, contudo, a textualização da política é mais ou menos restritiva dos sentidos que as comunidades disciplinares buscam instituir no currículo. A BNCC do ensino médio, por exemplo, não lista as disciplinas usuais do ensino médio como componentes curriculares obrigatórios, mas faz referência a elas no momento de discutir cada uma das áreas (ver, por exemplo, a p. 33) e mantém, desse modo, a tecnologia de organização curricular em movimento, ainda que tentando aprofundar a integração curricular por meio do que vem sendo denominado, pela BNCC, nova arquitetura da escola de nível médio.

Com essa discussão preliminar, quero apresentar a posição que busco defender neste artigo: a proposta de integração curricular apresentada pela BNCC do ensino médio não viabiliza a flexibilidade curricular a qual alude; pelo contrário, tende a ser restritiva de possibilidades de integração curricular por tentar controlar o projeto de vida dos jovens estudantes por meio de metas fixadas a priori. Assim sendo, a proposta de quebrar a disciplinaridade pode permanecer inalcançável, principalmente se ações não forem desenvolvidas, nos estados e municípios, para ampliar o diálogo com as comunidades disciplinares, tendo em vista as condições de trabalho e as identificações docentes nas escolas.

A interpretação dos textos da BNCC como política curricular no enfoque discursivo pós-fundacional com o qual opero é formulada em dado contexto de práticas discursivas e de relações de poder. Entram em jogo nesta interpretação ações como a proposta inicial da reforma do ensino médio ter sido apresentada sob a forma de uma Medida Provisória (MP 746/16, posteriormente aprovada com algumas mudanças como Lei 13.415/17), sem debate social, para introduzir mudanças na organização curricular e nas formas de 
financiar o ensino médio, com a indução de que recursos públicos possam ser usados pelo setor privado, sobretudo visando ofertar o itinerário de formação técnica e profissional (Ferreti \& Silva, 2017). Também fazem parte desse contexto discursivo: a proposta de que parte da carga horária do ensino médio possa ser realizada à distância, a partir de convênios entre os sistemas de ensino e instituições de educação à distância; a publicação da BNCC do ensino médio posteriormente à BNCC do ensino fundamental, em sinergia com as definições curriculares da Lei 13415/17 e rompendo com a lógica da educação básica; o menosprezo das condições necessárias para que uma ampla gama de itinerários formativos seja ofertada nas redes de ensino e das dificuldades para que exista uma efetiva articulação entre municípios e estados, de modo a dar conta dessa oferta; os registros altamente conservadores, para dizer o mínimo, que têm ganhado ressonância na sociedade brasileira, querendo retomar, de forma ambivalente, uma noção de escola ao mesmo tempo neutra em seus conteúdos e não neutra na defesa dos valores de certa concepção de família e nação brasileiras.

Minha interpretação considera também que tais orientações estão sendo implantadas nas escolas a partir deste ano (com previsão de finalizar em março de 2022), tendo por referência o Ministério da Educação de Abraham Weintraub, na presidência de Jair Bolsonaro. Outras práticas discursivas estão sendo organizadas, de forma a aprofundar o autoritarismo e o reacionarismo na educação e modificar a leitura da própria base, e tais práticas não são exclusivas do governo federal.

Para desenvolvimento desse tema, começo discutindo a noção de hibridismo com a qual tenho apoiado meu trabalho de investigação sobre organização curricular. Em seguida, discuto os limites da proposta de integração curricular e seu vínculo com a definição de projetos de vida dos estudantes, para depois discorrer sobre alguns dos impactos sobre as identificações docentes.

\section{Hibridismo como articulação discursiva}

Neste texto, opto por não desenvolver as discussões teóricas que embasam a investigação em pauta, de modo a privilegiar as conclusões da pesquisa. Aos interessados, indico em alguns momentos outros de meus textos, escritos ou não em parceria com integrantes de meu grupo de pesquisa, nos quais tais discussões teóricas são desenvolvidas.

Disponho-me, entretanto, a discutir brevemente sobre o hibridismo, uma vez que esta é uma das principais noções que tem perpassado meus projetos de pesquisa sobre organização curricular. Esta noção tem me ajudado a entender organizações curriculares que são ao mesmo tempo disciplinares e integradas, disciplinares e interdisciplinares, disciplinares e por competências ou projetos, ou que são tudo isso e muito mais ao mesmo tempo. Considero necessário tal destaque da noção hibridismo, uma vez que foram feitas 
mudanças importantes na abordagem de hibridismo desde meus primeiros trabalhos sobre organização curricular.

Nos primeiros trabalhos (Lopes, 2008), o hibridismo é assumido muito mais como mescla, justaposição ou bricolagem, processos de descoleção, desterritorialização e de formação de gêneros impuros, na linha teórica construída por García Canclini (1997). As políticas de currículo são interpretadas como marcadas por recontextualizações por hibridismo de distintos registros teóricos curriculares. Ainda que não haja a pretensão de entender esse processo como perda de alguma possível ideia de consistência e coerência originais, os textos são interpretados como tendo alguma referência a um contexto (um fora do texto) capaz de lhes garantir uma estrutura que sustente sua significação.

Hoje, procuro operar com o hibridismo que caracteriza as políticas de currículo na perspectiva de articulação de diferenças da teoria do discurso: processos de equivalência entre diferentes formas de organização curricular frente ao que se antagonizam, permanecendo em diferimento (Lopes, Cunha \& Costa, 2013). Todas as propostas curriculares, dentre elas a BNCC, são textos políticos, tentativas de representação de uma dada política, produzidos por práticas discursivas nas quais nós também nos inserimos. Ao longo da história do pensamento curricular, nós e muitos outros também falamos, escrevemos, produzimos ações em favor de disciplinas escolares, em favor da flexibilidade curricular ou da integração curricular, e mesmo criticando a disciplinaridade. Tais discursos - nossos discursos - também estão no jogo da significação das políticas curriculares.

A noção de hibridismo igualmente pode ajudar a questionar a forma esquemática e dicotômica com que as relações entre organização curricular e finalidades sociais vêm sendo realizadas. Dizer que o currículo disciplinar sempre remete suas finalidades a princípios não democráticos ou não-críticos, se assim preferirem, e o currículo integrado se remete sempre a princípios críticos e democráticos, inovadores e voltados aos interesses dos alunos é simplificar as múltiplas finalidades sociais em disputa nas mais diferentes políticas curriculares.

Afirmar o hibridismo que caracteriza o currículo não significa desconhecer que há relações de poder que sustentam uma estabilidade do currículo disciplinar, tornando a política curricular constituída por uma contraposição à organização disciplinar. Os processos híbridos, como articulações discursivas, se desenvolvem sob o imperativo de relações de poder que possibilitam a hegemonia de certas significações em detrimento de outras. Não há, todavia, um centro fixo de onde o poder emane, seja esse centro um governo, os partidos, instituições internacionais e multilaterais ou comunidades disciplinares, dentre elas as científicas.

Por sua vez, não há um referente que estabilize a interpretação desses textos, uma teoria curricular (ou qualquer teoria), uma estrutura econômica, qualquer estrutura capaz de fixar de uma vez por todas a interpretação afirmada. Toda leitura é contextual e situada e ter isso em mente no processo de pesquisar e ler as propostas curriculares - e mesmo este texto que aqui se apresenta - é também parte da interpretação. 


\section{Integração curricular para formar projetos de vida}

A noção de itinerários formativos não é inédita na história do currículo e faz parte de discursos que tentam propor a individualização do percurso formativo em nome de uma pedagogia diferenciada, entendida como capaz de combater o fracasso escolar (Perrenoud, 1998). Mais recentemente, por exemplo, vem fazendo parte das propostas de educação profissional. No texto que resultou de amplo debate sobre as Diretrizes Curriculares Nacionais para a Educação Profissional Técnica de Nível Médio, em 2010 (Brasil, 2010: p. 20), os itinerários formativos são concebidos como roteiro de estudos em um plano de formação continuada e como percursos formativos que o estudante poderá cursar no interior de processos regulares de ensino, possibilitando sua qualificação para fins de exercício profissional elou prosseguimento de estudos. Desse modo, é proposta a flexibilização da formação, no sentido de favorecer organizações curriculares diferentes nas instituições de educação profissional que possibilitem o reconhecimento de saberes e a certificação de atividades profissionais desenvolvidas em sistemas formais e não-formais. Tal concepção também busca atender aos processos de formação ao longo da vida, associando o itinerário formativo do estudante a suas futuras atividades profissionais e educativas, depois da formação em nível médio. Para tal, esse modelo se associa à certificação de competências desenvolvidas ao longo da vida profissional ${ }^{2}$.

Os itinerários formativos são incorporados pela resolução CNE/CEB nํ2, de 30 de janeiro 2012 (Brasil, 2012), que define diretrizes curriculares nacionais para o ensino médio, porém sem predefinição de quais são os possíveis itinerários a serem construídos. É proposto que a organização curricular desse nível de ensino ofereça tempos e espaços próprios para estudos e atividades que permitam itinerários formativos opcionais diversificados, a fim de melhor responder à heterogeneidade e pluralidade de condições, múltiplos interesses e aspirações dos estudantes, com suas especificidades etárias, sociais e culturais, bem como sua fase de desenvolvimento (p. 6).

Com a reforma do ensino médio, a proposta de organização dos currículos indica os itinerários formativos por áreas (linguagens e suas tecnologias; matemática e suas tecnologias; ciências da natureza e suas tecnologias; ciências humanas e sociais aplicadas; formação técnica e profissional), ou mesmo integrando diferentes áreas, sendo afirmado que busca atender o contexto local, na medida da possibilidade dos sistemas de ensino, e favorecer possíveis articulações com a educação profissional.

Não há maior aprofundamento de como tais possibilidades podem ser entendidas, tendo em vista as práticas instituídas nas escolas. Não são consideradas as dificuldades para que atividades sejam realizadas em distintas instituições ou mesmo as dificuldades para que uma mesma escola ofereça diferentes opções de itinerários formativos. É apontado apenas que em cada município deve haver oferta de mais de um itinerário formativo, que tais itinerários podem ser percorridos de forma concomitante ou sequencial, que deve haver atividades eletivas e de que são possíveis associações com outras instituições (Brasil, 2018b). 
Com essa orientação vaga, é favorecida a formulação de propostas de itinerários formativos para os sistemas de ensino, e mesmo para escolas, por instituições privadas que vêm atuando no apoio às políticas públicas educacionais. Há dentre elas a proposta de itinerário formativo Cultura Digital do Centro de Inovação para a Educação Brasileira $(\mathrm{Cieb})^{3}$ e o itinerário formativo $(\text { Steam })^{4}$ da Tríade Educacional ${ }^{5}$, que também se associa ao Cieb. Como já é do conhecimento de muitos, os mantenedores do Cieb são a Fundação Lemann, a Fundação Roberto Marinho, o Itaú Social, o Instituto Natura e o Instituto Península. Há também relações dessas organizações com o Todos pela Educação ${ }^{6}$, o Movimento pela Base $^{7}$ e o Instituto Inspirare ${ }^{8}$. Muitas das ações dessas entidades são divulgadas pelo Porvir ${ }^{9}$, portal de divulgação de inovações educativas organizado pelo Instituto Inspirare.

Havendo estreita relação dessas organizações com grandes empresas e instituições financeiras privadas, é possível reforçar o argumento, já difundido amplamente pela Associação Brasileira de Curriculo (ABdC) em nota pública, de que, muito mais do que uma mudança de organização curricular, a reforma do ensino médio visa favorecer a transferência de recursos de instituições públicas para instituições privadas. Para implementação dessa reforma, a associação entre essas instituições - e outras do mesmo gênero - e os sistemas públicos poderá vir a ser financiada com recursos públicos, nos moldes do que foi projetado, em 2017, para o Programa de Inovação Educação Conectada, apoiado pelo Banco Nacional do Desenvolvimento (BNDES) ${ }^{10}$ e desenvolvido pelo MEC em parceria com o Cieb.

Na medida em que as práticas instituídas nas escolas são disciplinares, torna-se ainda mais difuso como poderá ser realizada a certificação de competências desses itinerários formativos e que condições serão dadas às escolas para sua realização. Desse modo, o tão enfatizado protagonismo juvenil, associado à escolha do que estudar, torna-se submetido às possibilidades de escolas e redes, algo que, para seu estabelecimento, a juventude não tem o poder de interferir diretamente.

No Guia de Implementação da Reforma (Brasil, 2018b), é afirmado que se pode atender a integração curricular por meio de unidades curriculares, como disciplinas ou laboratórios, oficinas, clubes, observatórios, incubadoras, núcleos de estudos, núcleos de criação artística, múltiplas atividades, que também dependem das parcerias que as escolas e as redes de ensino venham a realizar com outras instituições sociais. Se por um lado tal flexibilidade pode ser benvinda, abrir espaços para experiências contextuais e para uma visão mais ampliada dos espaços educativos, questionando a ideia de que educação só se faz nas instituições formais, por outro pode ser uma flexibilização que se transforme em desempoderamento das escolas e mesmo em desescolarização, em sintonia com as atuais propostas de educação domiciliar.

Por sua vez, se for feita a articulação entre a diversidade das unidades curriculares não-disciplinares com o processo de redução da educação ao ensino registrado nas 
políticas curriculares brasileiras (Macedo, 2012), facilmente tal diversidade pode ser remetida à experiência de espaços de ensino (learning spaces), acentuando o processo de learnification da educação e de consequente individualização do ensino (Biesta, 2015).

Ensinar é uma das dimensões do processo de educar, mas não o esgota. Como já discutiu Macedo (2012), ao se colocar o conhecimento no centro do currículo, como vendo sendo feito em políticas curriculares, acaba-se por se conceber o aprendizado/ensino de um conhecimento como um processo no qual o conhecimento é algo externo ao sujeito, capaz de lhe garantir uma identidade também pré-estabelecida, construída por meio de um projeto pré-fixado. Por sua vez, o risco de conceber a diversidade de unidades curriculares como espaços de ensino é também o de reforçar o caráter individualizado do ensino, uma vez que o ensino se remete a algo que se faz consigo mesmo: a aprendizagem nesse sentido é fortemente individualista, quase neoliberal (Biesta, 2015).

Se, diferentemente, a educação é entendida como um processo que implica deixar emergir o sujeito como aquele que surge como o inesperado (Macedo, 2012: 734), que remete à possibilidade de que sujeitos se abram ao questionamento, em uma relação além e aquém do self (Biesta, 2015), se é uma produção cultural como inter-relação subjetiva mediada pela linguagem, tanto os processos de reduzir o currículo às atividades de ensino e à formação para atividades profissionais quanto o processo de criação de espaços de ensino que minimizem a interação em comunidades educativas são altamente redutores do que se entende por educação.

Na medida em que tais registros são articulados à concepção ainda mais restrita do próprio ensino propalada pelo governo Bolsonaro, voltado à ênfase dos processos de ensino e de aprendizagem em matemática, ciências e português e (...) à preparação para 0 mercado de trabalho (Brasil, 2019: 65-67), a prevalência de tal intepretação dos itinerários formativos como estudos voltados à construção de um self individualista é reforçada.

Principalmente porque ressoam em todo texto, incluindo a própria BNCC do ensino fundamental, rastros de um viés eficientista, na medida em que as aprendizagens consideradas necessárias são aquelas sintonizadas com os desafios da sociedade contemporânea, como definido na Introdução desta BNCC (p. 14; citada p. 465). Pela Resolução CNE/CEB nº 3/2018 (Brasil, 2018d), que atualiza as Diretrizes Curriculares para o Ensino Médio, os itinerários formativos devem ser orientados pelo perfil de saída almejado para o estudante com base nos Referenciais para a Elaboração dos Itinerários Formativos, e deve ser estabelecido pela instituição ou rede de ensino, considerando os interesses dos estudantes, suas perspectivas de continuidade de estudos no nível pós-secundário e de inserção no mundo do trabalho (p. 8), num arranjo que tanto aponta para a pluralidade de interesses dos alunos quanto para o controle desses interesses pela inserção no mundo do trabalho.

Por sua vez, no Guia de Implementação da Reforma e na BNCC do ensino médio, é feita menção ao ajuste dos itinerários formativos ao projeto de vida dos estudantes. Como conceber o ajuste a um projeto de vida? Por que supor que a juventude pode ou 
deve antecipar seu projeto de vida, como se as experiências educativas estivessem obrigatoriamente sintonizadas com um futuro pré-programado no presente, ao invés de atenderem demandas e expectativas urgentes da vida dos estudantes hoje? Tal enfoque pode apenas estar tentando antecipar decisões, submeter experiências imprevistas a um dado projeto de futuro que não faz obrigatoriamente sentido para as singularidades juvenis, mas está submetidos aos anseios de grupos sociais que supõem saber dizer como o futuro dos jovens deve (e pode) ser.

Contribuindo para minimizar as possibilidades de uma integração curricular que se volte aos interesses e expectativas dos jovens, bem como reforçando os rastros instrumentais da proposta, é apresentada a organização curricular por competências. Uma competência é definida na BNCC como: a mobilização de conhecimentos (conceitos e procedimentos), habilidades (práticas, cognitivas e socioemocionais), atitudes e valores para resolver demandas complexas da vida cotidiana, do pleno exercício da cidadania e do mundo do trabalho (Brasil, 2018a: 8). Em seguida é afirmado que tais competências visam a transformação da sociedade, tornando-a mais humana, socialmente justa e, também, voltada para a preservação da natureza (Idem).

Não desconsidero que as competências são dimensões possíveis da formação educativa. Questiono, contudo, a proposta de remeter toda a organização curricular às competências, submetendo a educação ao registro instrumental de um saber-fazer, voltado a uma vaga noção de cidadania e de trabalho. Com isso, a educação mais uma vez permanece reduzida ao ensino e o ensino, por sua vez, fica restrito ao atendimento de metas de aprendizagem vinculadas ao saber fazer e à resolução de problemas associados a demandas da vida cotidiana (como se tais demandas do que se supõe ser a vida cotidiana fossem as mesmas para todas e todos).

Diferentemente dos PCN, que listavam competências por disciplinas, produzindo outra organização híbrida, na BNCC do ensino médio as competências são listadas por áreas, sendo cada competência dividida em habilidades, compondo a formação geral básica de até 1800 horas, a ser complementada pelos itinerários formativos. Tais habilidades nos Referenciais Curriculares para elaboração dos itinerários formativos (Brasil, 2018c) são por sua vez vinculadas aos eixos estruturantes, definidos na Resolução CNE/CEB no 3/2018 (Brasil, 2018d): investigação científica, processos criativos, mediação e intervenção sociocultural, e empreendedorismo.

Sem apoio das disciplinas, esse formato tanto pode produzir um aligeiramento de conteúdos como pode ser lido de forma conservadora, mantendo as atividades das escolas exatamente como são hoje, nada se fazendo para combater o que se julga merecedor de crítica no currículo do nível médio. Por sua vez, a ligação estabelecida entre formação por competências, formação para o mundo do trabalho e o exercício da cidadania desconsidera a necessidade de discutir o que se entende por trabalho e cidadania, bem como remete a uma ideia de que ser cidadão trabalhador é o limite da significação das 
singularidades humanas. Por que a educação de nível médio tem que estar submetida ao trabalho como projeto de vida? Mais uma vez reitero o quanto essa organização curricular parece querer controlar o futuro dos jovens, instando-os a definir seus projetos de vida tanto no que diz respeito ao estudo e ao trabalho como também no que concerne às escolhas de estilos de vida saudáveis, sustentáveis e éticos (Brasil, 2018: 463) via itinerários formativos, sem admitir que esse futuro - como porvir - não é algo programável ou previsível.

Isso porque, se por um lado o texto da BNCC para o ensino médio afirma que em lugar de pretender que os jovens apenas aprendam o que já sabemos, o mundo deve lhes ser apresentado como campo aberto para investigação e intervenção (...) (Brasil, 2018: 463), por outro a proposta de metas comuns de aprendizagem, de organização centralizada de competências e de itinerários formativos contraria essa afirmação, apostando justamente na ideia de que os jovens devem aprender o que já sabemos, pois apenas o que já sabemos pode ser pré-definido por nós como competências e habilidades para serem avaliadas por meio dos exames centralizados. Em outros termos, o texto da BNCC afirma constantemente o protagonismo juvenil, a pluralidade, a diversidade, a construção do currículo na escola, porém a organização por competências contraria tais princípios, tentando impor limites e metas às possíveis formas de organização curricular na escola e mesmo aos possíveis e diferentes itinerários formativos. Tal processo, por sua vez, pode vir a ter impacto significativo nas identificações docentes.

\section{Identificações docentes}

Considerando o modo impositivo como a reforma do ensino médio foi instaurada, abortando por meio de uma Medida Provisória um processo de reforma em curso (Ferreti \& Silva, 2017; Silva, 2018), bem como a desconsideração de um debate com comunidades disciplinares, haja vista a reação inicial frente às disciplinas que se viram excluídas da reforma - notadamente Sociologia, Filosofia, Artes e Educação Física -, é possível afirmar sua inserção em uma lógica autoritária. Tal lógica desconsidera que mudanças, dentre elas as curriculares, sempre estão em um processo de negociação com práticas instituídas.

Como já discuti em outro texto (Lopes, 2018b), permanência e mudança precisam ser pensadas de forma mutuamente constitutiva: dizer o mesmo, é de algum modo desconstruir a tentativa de ser idêntico; se dispor à mudança, é sempre partir de algo que já começou. Tais relações se conectam com a dinâmica das articulações que produzem políticas de currículo híbridas. Desse modo, organizar projetos educativos por meio de propostas curriculares, defender a constituição de certas identidades, fazer valer certas tradições, lutar para manter o que supomos ser o melhor para os jovens deve ser pensado como articulado à mudança social, afirmando que tais projetos, identidades e tradições estão inseridos em uma política que pressupõe negociar com o outro o que se pretende instituir. Pressupor normas que 
estabeleçam de uma vez por todas qual o melhor projeto educativo, qual o melhor conhecimento, as melhores atividades na escola, os valores válidos, o melhor currículo, o melhor porvir pode facilmente se inserir na lógica de decidir de forma autoritária no lugar do outro.

Sem considerar as trajetórias disciplinares em curso na sociedade e a organização disciplinar da formação de professores, a organização por áreas, tal como proposta na reforma do ensino médio, pode vir a ser apenas uma organização artificial que visa "resolver" a falta de professores de certas disciplinas nas escolas de nível médio. Igualmente, tanto pode não quebrar, como pretendido, a lógica disciplinar acadêmica do nível médio de ensino, como pode produzir maior insegurança e sensação de fracasso entre os docentes.

Goodson (2014), analisando o processo histórico das mudanças curriculares no Reino Unido nos últimos quarenta anos, conclui que os grupos profissionais de professores e acadêmicos foram substituídos por uma gama de grupos de interesses políticos e comerciais, voltados à colonização da educação pública como um local para acumulação de lucro. Com isso, ele destaca que o compromisso pessoal e profissional dos educadores, que deveria ser o cerne de qualquer reforma, está ausente, tornando os professores e professoras, simultaneamente, indiferentes e profundamente hostis às reformas.

Não cabe, a meu ver, simplesmente replicar tais conclusões para o Brasil. O próprio Goodson salienta que as orientações curriculares seguem de um país a outro, mas são sempre refratadas, sujeitas a outras significações. Na minha interpretação, são sempre hibridizadas, uma vez que são situadas e submetidas a outras relações de poder. Igualmente, nem sempre considero que as finalidades de uma reforma se inserem na produção direta de lucro. Há um conjunto de demandas que incluem o lucro, mas não se limitam a ele, na medida em que se busca formar subjetividades que, na falta de melhor adjetivo, denomino neoliberais, nas quais é considerado que também vale a pena investir financeiramente. Ainda assim, como destaca Goodson, desconsiderar o impacto das reformas curriculares nas identificações docentes, notadamente disciplinares, pode ser um caminho fácil para a indiferença e hostilidade justamente daqueles que realizam o currículo nas escolas.

Com isso não estou querendo defender que as disciplinas são intocáveis ou que as áreas não são uma forma legítima de organização curricular: apenas quero salientar que modificar a organização curricular não é apenas modificar uma listagem de conteúdos, competências e habilidades, mas interferir em práticas discursivas educacionais e identificações docentes.

Há necessidade, assim, de que se aprofunde a inter-relação com as comunidades disciplinares nessa política, sem considerar a organização disciplinar simplesmente como um "mal" a ser superado. Não é de hoje que diferentes estudos (Darby, 2006; Tytler, Symington, Darby, Malcom \& Kirkwood, 2011) concluem como as características disciplinares são decisivas para a formação de culturas de professoras e professores. $\mathrm{O}$ pertencimento a comunidades disciplinares influencia formas de ensinar, modos de interpretação dos textos curriculares, percepções e autoimagem dos docentes, ao mesmo 
tempo em que a organização disciplinar mantém relação direta com sua carga de trabalho - disciplinas mais valorizadas tendem a ter maior carga horária e, portanto, levam seus docentes a terem menos estudantes sob sua responsabilidade.

Na medida em que incorporo uma noção discursiva de comunidade disciplinar (Costa \& Lopes, 2018), não há uma formação comum ou saberes primordiais ou mesmo compromissos epistemológicos consensuais a serem apropriados pelos integrantes de uma comunidade disciplinar, que, sem eles, dela estariam excluídos. A comunidade disciplinar é constituída por identificações equivalencias, sempre discursivas, frente a um exterior constitutivo com o qual se estabelece um antagonismo, em uma dada política específica. Tais discursos subjetivam os coletivos que falam em nome da disciplina, para além dos grupos profissionais que se constituem em torno do conhecimento disciplinar. No caso da reforma do ensino médio, por exemplo, as lutas políticas em defesa das disciplinas escolares Sociologia e Filosofia não se fizeram exclusivamente - e talvez nem prioritariamente - a partir das ações de docentes dessas disciplinas, mas por todas aquelas e todos aqueles que constituem uma representação dessas disciplinas como espaço de pensamento crítico e formação para a cidadania.

Nesse sentido, os esforços para reinterpretar a BNCC do ensino médio, nos estados e municípios, desenvolvendo o que se concebe como uma implementação da reforma, só poderá almejar algum sucesso no aprofundamento da integração curricular se assumir o que já vem sendo discutido há muito tempo nas pesquisas em políticas de currículo: professoras e professores são também produtores da política e o fazem por meio das comunidades disciplinares.

\section{Considerações finais}

Muito mudou no País após a publicação da BNCC do ensino médio. Outras lutas políticas se desenvolvem, nos diferentes estados e municípios, na leitura e interpretação da base, buscando colocá-la em prática. O texto da BNCC será interpretado de outras tantas formas, que não há como prever agora. Nessas interpretações, certamente haverá influências do fato de estarmos sendo governados, em nível federal, por um projeto que quer se antagonizar a uma educação supostamente voltada à doutrinação e propagação de ideologias político-partidárias em ambiente escolar (Brasil, 2019: p. 66). Desse modo, ao mesmo tempo em que é afirmado que a formação e a valorização dos professores são pilares fundamentais de uma educação de qualidade (Idem), professoras e professores são identificados como doutrinadores e inimigos do projeto que se pretende instaurar.

Todo trabalho com a BNCC terá assim que enfrentar a fantasia ${ }^{11}$ que se construiu nesse país de que a educação ameaça a família brasileira, seus valores, sua religião, sua existência, impondo um discurso de gênero e sexualidade e um discurso de esquerda. 
Não há como apresentar aqui o processo que levou à construção desse discurso - um discurso que produziu efeitos ainda mais amplos e perversos do que a eleição de Bolsonaro à Presidência da República.

Quero apenas salientar o quanto esse discurso fantasmático produz identidades para a escola, mobiliza subjetividades que precisarão ser enfrentadas por todas aquelas e todos aqueles que consideram que a democracia é tanto a possibilidade de manter os espaços de poder abertos à disputa quanto de bloquear tentativas de destruição do diferir.

Esse discurso fantasmático não é nada fácil de combater. Ele tanto constrói a identidade de um inimigo (nós, supostos como capazes de produzir o horror e a privação), que precisa ser combatido quanto projeta a aceitação de discursos salvacionistas, que são significados como capazes de impedir a desordem, a desorganização e a destruição das identidades sociais (a identidade da família ou da nação brasileira, por exemplo). $\mathrm{O}$ trabalho de desconstruir tais discursos não pode ser, a meu ver, a simples afirmação de uma oposição (de um outro lado), a simples resistência (em qualquer lugar que se esteja). Exigirá a reinvenção de formas de fazer política, tentando desconstruir tanto a ideia de horror quanto a ideia de salvação com as quais estamos sendo subjetivados.

Recebido em: 20/05/2019 e aprovado em: 01/06/2019

\section{Notas}

1 Uma primeira versão resumida deste texto foi apresentada como conferência de abertura do III Encontro Nacional Ensino e Interdisciplinaridade (Enacei), realizado na Universidade do Estado do Rio Grande do Norte, em Mossoró, em maio de 2019. Pesquisa financiada pelo CNPq, Faperj e Capes (código de financiamento 001).

2 Na versão final das Diretrizes Curriculares Nacionais para a Educação Profissional (Brasil, 2012a), a concepção de itinerários formativos permanece e assume outros contornos que não serão aqui analisados.

3 http://www.cieb.net.br

4 Como a própria proposta informa, Steam é "um acrônimo, da língua inglesa, usado para designar a combinação das áreas de Ciências, Tecnologia, Engenharia, Artes e Matemática".

5 http://www.triade.me

6 https://www.todospelaeducacao.org.br/

7 http://movimentopelabase.org.br/

8 http://inspirare.org.br/

9 http://www.porvir.org

10 http://portal.mec.gov.br/secretaria-de-regulacao-e-supervisao-da-educacao-superior-seres/30000-uncategorised/57671-plataforma-integrada 
11 Utilizo fantasia como abordado por Clarke (2012): um discurso fantasmático; não é uma ilusão nem o oposto de realidade. A fantasia, tal como o discurso hegemônico, oculta as contingências dos discursos, suaviza contradições, antagonismos e deslocamentos, em nome de uma concepção que se pretende completa, harmônica, consensual e capaz de preencher o vazio constitutivo do ser.

\section{Referências}

BIESTA, Gert. What are schools for? An interview with Gert Biesta on the learnification of school buildings and education, Architecture and Education, 2015. https://architectureandeducation. org/2015/05/24/what-are-schools-for-gert-biesta-on-the-learnification-of-school-buildings-and-education/

BRASIL. Ministério da Educação. Diretrizes Curriculares Nacionais para a Educação Profissional Técnica de Nível Médio em debate. Brasília, DF: MEC, 2010.

BRASIL. Conselho Nacional de Educação. Câmara da Educação Básica. Resolução CNE/CEB no 2, de 30 de janeiro de 2012. Institui as Diretrizes Curriculares Nacionais para o Ensino Médio. Brasília, DF: MEC, 31 de janeiro de 2012a.

BRASIL. Conselho Nacional de Educação. Câmara da Educação Básica. Resolução CNE/CEB nº 6, de 30 de janeiro de 2012. Institui as Diretrizes Curriculares Nacionais para a Educação Profissional. Brasília, DF: MEC, 20 de setembro de 2012b.

BRASIL. Lei de Diretrizes e Bases da Educação Nacional. Lei n⿳0 13.415/2017, de 13 de fevereiro de 2017. Disponível em: < http://www.planalto.gov.br/ccivil_03/_ato2015-2018/2017/lei/L13415.htm>.

BRASIL. Ministério da Educação. Base nacional comum curricular. Brasília, DF: MEC, 2018a.

BRASIL. Ministério da Educação. Guia de implementação da Base nacional comum curricular. Brasília, DF: MEC, 2018b.

BRASIL. Ministério da Educação. Referenciais Curriculares para elaboração dos itinerários formativos. Brasília, DF: MEC, 2018c.

BRASIL. Conselho Nacional de Educação. Câmara da Educação Básica. Resolução CNE/CEB no 3, de 21 de novembro de 2018. Atualiza as Diretrizes Curriculares Nacionais para o Ensino Médio. Brasília, DF: MEC, 2018d.

BRASIL. Presidência da República. Mensagem ao Congresso Nacional, 1aㅗ Sessão Legislativa Ordinária da 56 $6^{\text {a }}$ Legislatura. Brasília: Presidência da República, 2019. Disponível em http://www.casacivil.gov. br/central-de-conteudos/downloads/mensagem-aocongresso-2019/@@download/file/Mensagem-aoCongresso-2019.pdf>

CLARKE, Matthew. The (absent) politics of neo-liberal education policy, Critical Studies in Education, Abingdon, United Kingdom, Taylor and Francis 53:3, 297-310, 2012. DOI: 10.1080/17508487.2012.703139

COSTA, Hugo; LOPES, Alice Casimiro. A comunidade disciplinar em Goodson: impasses em um registro pós-estrutural. Revista Brasileira de Educação, Rio de Janeiro, ANPEd, v. 21, p. 1009-1032, 2016. http://dx.doi.org/10.1590/S1413-24782016216751

COSTA, Hugo; LOPES, Alice Casimiro. School subject community in times of death of the subject.

Policy Futures in Education (online), Auckland, New Zealand, SAGE Pub, v. 1, p. 1-17, 2018. https://doi. org/10.1177/1478210318766955 
CUNHA, Érika; LOPES, Alice Casimiro. Base Nacional Comum Curricular: regularidade na dispersão. Investigación Cualitativa, Urbana, IL, USA, International Association of Qualitative Inquiry v. 2, p. 2335, 2017. http://dx.doi.org/10.23935/2016/02023

DARBY, Linda. Negotiating mathematics and Science school subject boundaries: the role of aesthetic understanding. In: M. V. Thomase (Ed.), Science education in focus (pp. 55-82). New York: New Science Publishers, 2006.

FERRETI, Celso; SILVA, Monica RIBEIRO DA. Educação \& Sociedade, Campinas, CEDES, v. 38, n. 139, p. 385-404, abr.-jun., 2017.

GARCÍA CANCLINI, Néstor. Culturas Híbridas: estratégias para entrar e sair da modernidade. São Paulo: EDUSP, 1997.

GOODSON, Ivor. School subjects and curriculum change: case studies in curriculum history. London: Croom Helm, 1983.

GOODSON, Ivor. Context, curriculum and professional knowledge, History of Education: Journal of the History of Education Society, Abingdon, United Kingdom, Taylor and Francis, 43: 6, 768-776, 2014 DOI:1 0.1080/0046760X.2014.943813

LOPES, Alice CASIMIRO. Políticas de integração curricular. Rio de Janeiro: EdUerj/Faperj, 2008. 184p. Disponível em: www.eduerj.uerj.br

LOPES, Alice CASIMIRO. Por um currículo sem fundamentos. Linhas Críticas, Brasília, UnB, v. 21, p. 445-466, 2015.

LOPES, Alice CASIMIRO. Apostando na produção contextual do currículo. In: Aguiar, Márcia Angela \& Dourado, Luiz Fernandes. A BNCC na contramão do PNE 2014 -2024. Goiânia, ANPAE, 2018a, p. 1-5.

LOPES, Alice CASIMIRO. In: Políticas de currículo em um enfoque discursivo: notas de pesquisa. In: Alice CASIMIRO LOPES; Anna Luiza MARTINS DE OLIVEIRA; Gustavo Gilson de OLIVEIRA. (Org.). A Teoria do Discurso na Pesquisa em Educação. Recife: Editora da UFPE, 2018b, v. 1, p. 133-167.

LOPES, Alice CASIMIRO; CUNHA, Érika; COSTA, Hugo. Da recontextualização à tradução: investigando políticas de currículo. Currículo sem Fronteiras, Pelotas, UFPel, v. 13, p. 392-410, 2013. http://www.curriculosemfronteiras.org/vol13iss3articles/lopes-cunha-costa.pdf

MACEDO, Elizabeth. Currículo e conhecimento: aproximações entre educação e ensino. Cadernos de Pesquisa, São Paulo, Fundação Carlos Chagas, v. 42, n. 147, p. 716-737, 2012. http://www.scielo.br/pdf/ $\mathrm{cp} / \mathrm{v} 42 \mathrm{n} 147 / 04 . p d f$

MACEDO, Elizabeth; LOPES, Alice Casimiro. A estabilidade do currículo disciplinar: o caso das ciências. In: Alice CASIMIRO LOPES; Elizabeth MACEDO. (Org.). Disciplinas e integração curricular: história e políticas. Rio de Janeiro: DP\&A, 2002, p. 73-94

PERRENOUD, Philippe. ¿A dónde van las pedagogías diferenciadas? Hacia la individualización del currículoy delositinerariosformativos. Educar, Barcelona, Universidad deBarcelona, n. 22-23,1998, p.11-34.

Silva, Monica RIBEIRO da. A BNCC da reforma do ensino médio: o resgate de um empoeirado discurso. Educação em Revista, Belo Horizonte, UFMG, V. 34, p. 1-15, 2018. http://dx.doi.org/10.1590/01024698214130

TYTLER, Russell; SYMINGTON, David; DARBY, Linda; MALCOLM, Cliff \& KIRKWOOD, Valda (2011). Discourse communities: a framework from which to consider professional development for rural teachers of science and mathematics. Teaching and Teacher Education, Amsterdam, Elsevier, 27(5), 871879. DOI: $10.1016 /$ j.tate.2011.02.002 